\title{
Utilidad del examen elemental de orina para el diagnóstico de infecciones urinarias en pacientes pediátricos
}

\section{Usefulness of elemental urine test for the diagnosis of urinary tract infections in pediatric patients}

\section{Utilidade do teste de urina elementar para o diagnóstico de infecções urinárias em pacientes pediátricos}

Dolores B. Erazo-López I

dolores.erazol@ug.edu.ec

\author{
Erika T. Nieto-Erazo IV \\ erikanieto@gmail.com
}

Elizabeth A. Valencia-Lainez ${ }^{\text {II }}$

Mauro S. Nieto-Aguirre ${ }^{\mathrm{V}}$

elivalenciala@gmail.com mauro.nietoa@ug.edu.ec

Gina C. Johnson-Hidalgo ${ }^{\text {III }}$

gina.johnson@ug.edu.ec

Recibido: 30 de enero de $2017 *$ Corregido: 20 de febrero de $2017 *$ Aceptado: 20 junio de 2017

I. Magister en Bioquímica Clínica; Química y Farmacéutica; Universidad de Guayaquil, Guayaquil, Ecuador.

II. Química y Farmacéutica; Universidad de Guayaquil, Guayaquil, Ecuador.

III. Magister en Bioquímica Clínica; Diploma Superior en Marketing Farmacéutico; Química y Farmacéutica; Universidad de Guayaquil, Guayaquil, Ecuador

IV. Médica, Universidad de Guayaquil, Guayaquil, Ecuador.

V. Especialista en Cirugía General; Diploma Superior en Docencia Universitaria; Doctor en Medicina y Cirugía; Universidad de Guayaquil, Guayaquil, Ecuador. 


\section{Resumen}

La investigación se realizó en el año 2013 en el Barrio Nigeria de la Isla Trinitaria se escogió el Barrio antes mencionado por la falta de servicios básicos, las condiciones insalubres en que juegan los niños, los disminuidos espacios en los hogares lo convierten en un sector vulnerable para muchos tipos de enfermedades, entre ellas la infección de vías urinarias, si no se da el correcto tratamiento puede conllevar a la enfermedad renal crónica no transmisible (ERCNT) y muchas veces llegar a la insuficiencia renal. El objetivo del estudio fue evaluar el examen elemental de orina en niños de edades pediátricas, en el sector de Nigeria, apoyado en un estudio experimental de proyecto formativo de los alumnos de Quinto año de la Facultad de Ciencias Químicas, a los que se realizaron encuestas básicas.

El resultado de esta investigación se observó la presencia de bacterias en un 5\% de los pacientes estudiados, se encontró el $10 \%$ de presencia de cristales de oxalato de calcio (++), los mismos que él puede producir cálculos renales. Cristales fosfatos de amonio y magnesio $15 \%$ estos no presentan sintomatología clínica.

Como conclusión la incidencia que se encontró en estos pacientes fue del 5\%. Se sugiere hacer un estudio con una población más numerosa para poder obtener una visión más amplia de la investigación para tomar acciones preventivas y evitar enfermedades renales crónicas que produzcan un aumento en la economía familiar y en el producto interno del País.

Palabras clave: Infecciones urinarias; análisis de orina-niños; riñón. 


\section{Abstract}

The research was conducted in 2013 in the neighborhood of Trinity Island Nigeria Barrio above by the lack of basic services, unsanitary conditions in which children play, the handicapped spaces in homes make it a vulnerable sector was chosen for many types of diseases, including urinary tract infection, if not given the correct treatment can lead to chronic kidney disease not transmissible (ERCNT) and often reach kidney failure. The aim of the study was to evaluate the elemental urine test in pediatric age children in the area of Nigeria, supported by an experimental study of formative project of Fifth year students of the Faculty of Chemical Sciences, which surveys were conducted basic.

The result of this research the presence of bacteria in 5\% of patients studied was observed, $10 \%$ presence of calcium oxalate crystals $(++)$, the same as it can cause kidney stones found. Crystal's magnesium ammonium phosphates $15 \%$ do not have clinical symptoms.

In conclusion, the incidence was found in these patients was 5\% . The suggests a study with a larger order to get a broader view of research to take preventive actions and avoid chronic renal diseases that produce an increase in the population family and the domestic product of the country's economy.

Key words: Urinary infections; urine-child analysis; kidney. 


\section{Introducción.}

La infección urinaria es una de las patologías infecciosas más frecuentes en pediatría, incluye uretra, vejiga, riñón o próstata. ${ }^{1-3}$

La prevalencia de la IU depende de la edad y del sexo y es más frecuente en niñas. La frecuencia de la primera infección urinaria es mayor durante el primer año de vida para ambos sexos y la mayoría son Pielonefritis aguda "PNA". La prevalencia en el primer año de vida es del 6,5\% para las niñas y del 3,3\% para los niños. Después del primer año de la prevalencia baja en los niños al $2 \%$ pero sube en las niñas al $8 \%$. La primera IU clasificada como cistitis es más frecuente en niñas de 2 a 6 años. ${ }^{4-6}$

Las condiciones socioeconómicas que se presentan en un barrio urbano marginal denominado Nigeria ubicado en La Isla Trinitaria de Guayaquil, se estimó trabajar con un universo de 20 niños y adolescentes entre las edades de 5 -14 años a los cuales se les realizará un examen general de orina, con los resultados se determinará los factores influyentes y predisposiciones que causan las infecciones urinarias. Para esto se realizó una visita de campo para observar el lugar donde viven los pacientes, sus condiciones y sus actividades. ${ }^{7,8}$

Los procedimientos la higiene personal y las formas de los juegos en dichos niños, presentan factores que predisponen a infecciones de vías urinarias, se realizó examen general de orina para investigar las posibles causas o enfermedades.

La presentes investigación tiene como objetivo demostrar la utilidad del examen elemental de orina para el diagnóstico presuntivo de las enfermedades urinarias en pacientes pediátricos en el Sector de Nigeria - Isla Trinitaria. 


\section{Materiales y métodos.}

\section{Enfoque Metodológico}

Hermenéutico: la sistematización de dicho proyecto se dirige en crear un análisis explicativo de la experiencia de un sector urbano marginal por sus condiciones ambientales y la falta de agua potable, se pensó encontrar en el examen elemental de orina, bacteria y piuria que serviría de guía para el diagnóstico de infecciones de vías urinarias en los niños de etapa pediátrica.

\section{Lugar de la experiencia}

Barrio Nigeria, ubicado en La Isla trinitaria de la Ciudad de Guayaquil

\section{Población meta}

Se trabajó con un universo de 20 pacientes, entre ellos niños y adolescentes de edades entre 5 a 14 años.

\section{Técnicas y procedimientos.}

Para obtener los datos requeridos, es necesario emplear una entrevista al niño o sus padres que incluya su nombre, edad, si están tomando medicamentos; y en lo posterior se los instruye para que aprendan la manera correcta de recoger una muestra en el recolector de orina entregado. Al día siguiente se recogen las muestras en cada uno de los hogares, y se procesan en el laboratorio de Análisis Químico Clínico de la Facultad de Ciencias Químicas de la Universidad de Guayaquil. 
Las muestras se procesan mediante el Examen General de Orina, el cual comprende un análisis físico, verificado su olor, color y aspecto; como segundo punto se procede al examen químico en el que se analizan parámetros de, $\mathrm{pH}$, densidad, sangre, glucosa, urobilinógeno, ketamina, bilirrubina, nitritos y nitratos y leucocitos. Finalmente el análisis microscópico está incluido en este examen general, para determinar la presencia de bacterias, cristales, células, etc. Las técnicas de procesamiento de estos análisis se encuentran especificadas en el marco teórico de esta investigación.

El Examen General de Orina nos proporciona los datos para determinar los parámetros que influyen en las infecciones urinarias en los niños y niñas. De estos datos obtenidos se logra recolectar un cuadro de datos.

\section{Resultados.}

Posteriormente se procede a reunir los datos y establecer porcentajes de cada uno de los parámetros obtenidos de las muestras analizadas.

\begin{tabular}{|c|c|c|}
\hline & FÍSIC \\
\hline Aspecto & Olor & Color \\
\hline Lig. turbio & Característico & Amarillo \\
\hline $100 \%$ & $100 \%$ & $100 \%$ \\
\hline
\end{tabular}

\begin{tabular}{|c|c|c|c|c|c|c|c|}
\hline \multicolumn{7}{|c|}{ QUÍMICO } \\
\hline Urobilinógeno & Glucosa & Cetonas & Bilirrubin & Proteínas & Nitrito Hemoglobina & Leucocitos \\
\hline $0 \%$ & $0 \%$ & $0 \%$ & $0 \%$ & $0 \%$ & $5 \%$ & $0 \%$ & $0 \%$ \\
\hline
\end{tabular}




\begin{tabular}{|c|c|c|c|c|c|c|c|c|}
\hline \multicolumn{9}{|c|}{ QUÍMICO } \\
\hline \multicolumn{4}{|c|}{$\mathrm{pH}$} & \multicolumn{5}{|c|}{ Densidad } \\
\hline 5 & 6 & 8 & 9 & 1,005 & 1,015 & 1,020 & 1,02 & 1,030 \\
\hline $45 \%$ & $45 \%$ & $5 \%$ & $5 \%$ & $5 \%$ & $15 \%$ & $10 \%$ & 40 & $30 \%$ \\
\hline
\end{tabular}

\begin{tabular}{|c|c|c|c|c|c|c|c|}
\hline \multicolumn{8}{|c|}{ MICROSCÓPICO } \\
\hline 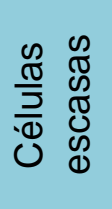 & 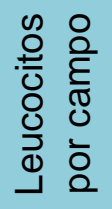 & 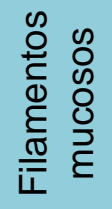 & 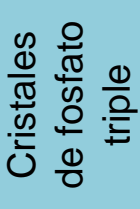 & 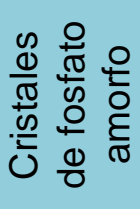 & 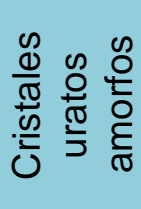 & 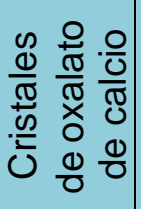 & 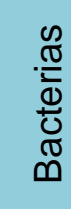 \\
\hline $95 \%$ & $70 \%$ & $20 \%$ & $5 \%$ & $10 \%$ & $25 \%$ & $10 \%$ & $5 \%$ \\
\hline
\end{tabular}

\section{Análisis e interpretación de los resultados}

Determinar mediante el examen físico químico de orina la posibilidad de infecciones urinarias.

Los pacientes pediátricos En el examen físico químico se encontraron el $5 \%$ de resultados positivo la presencia de $\mathrm{pH}$ alcalino, la turbidez en la orina y presencia de bacterias.

Observar microscópicamente el sedimento urinario en búsqueda de elementos indicadores de infección.

En el sedimento urinario se observó presencia de bacteria (++), cristales de oxalatos de calcio, en un $10 \%$, observándose también uratos amorfos en $25 \%$ y fosfatos triple de amonio y magnesio no presentan relevancia clínica. 
Establecer si las condiciones medio ambientales son factores determinantes en las infecciones urinarias.

Las condiciones insalubres en la que juegan los niños, hacinamiento que vive, la falta de agua potable se demuestra que los factores predisponen a diversas infecciones.

Se demuestra que del $100 \%$ de los pacientes estudiados el examen elemental de orina se encontró 5\% presentan bacteria (++), $\mathrm{pH}$ alcalino ,densidades de 1.030 determinan sospechas de solutos anormales la presencia de turbidez puede indicar presencia de bacterias o células abundantes que ayudarían diagnóstico temprano de infecciones urinarias.

\section{Conclusiones.}

Determinar mediante el examen físico químico de orina la posibilidad de infecciones urinarias.

Se determinó mediante el análisis con tiras reactivas que un 5\% de los pacientes estudiados presentó nitritos positivo, lo que indica presencia de posible infección, ya que las bacterias reducen los nitratos presentes en la orina a nitritos. El $\mathrm{pH}$ alcalino indica presencia de fosfatos, uratos y bacterias que alcalinizan la orina. Concluyendo que el examen físico y químico de la orina son indicadores importantes del estado de salud.

Observar microscópicamente el sedimento urinario en búsqueda de elementos indicadores de infección.

Se confirmó la presencia de bacterias en el sedimento urinario en un 5\%. 
Establecer si las condiciones medio ambientales son factores determinantes en las infecciones urinarias.

El estudio demostró que a pesar de las condiciones de insalubridad se determinó que un $5 \%$ IU es pequeño debido al universo que se realizó en el proyecto formativo.

\section{Bibliografía.}

1. Echevarría-Zarate Juan, Sarmiento Aguilar Elsa, Osores-Plenge Fernando. Infección del tracto urinario y manejo antibiótico. Acta méd. Peruana. 2006 Ene; 23(1): 26-31.

2. Howes DS, Henry SM. Urinary Tract Infection, Female. 2005. Emedicine: http://www.emedicine.com/EMERG/topic626.htm

3. Komaroff AL. Urinalysis and urine culture in women with dysuria. Ann Intern Med. 1986;104: 212-218.

4. Caggiani Marina, Barreiro Ana, Schol Paloma. Infección urinaria en niños internados: características clínicas, bacteriológicas e imagenológicas. Arch. Pediatr. Urug. 2002 Dic; 73(4): 203-211.

5. Satriano R, Caggiani M. Infección Urinaria. In: Bello O, Sehabiague G, Prego J, de Leonardis D. Pediatría: urgencias y emergencias. Montevideo: Bibliomédica, 2002: 127-36.

6. Winberg J, Andersen HJ, Bergstrom T. Epidemiology of syntomatic urinary tract infections in childhood. Acta Ped. Scand 1974; Suppl. 252: 1-20.

7. García Vera C. Infecciones urinarias. Rev Pediatr Aten Primaria. 2013 Jun; 15( Suppl 23 ): 71-80.

8. Eiros Bouza JM, Ochoa Sangrador C. Perfil etiológico de las infecciones urinarias y patrón de sensibilidad de los uropatógenos. An Pediatr (Barc). 2007; 67: 461-8. 